\title{
Análise da produção científica sobre o caratê em língua portuguesa
}

\author{
Scientific production on karate in portuguese language
}

DOI: http://dx.doi.org/10.36453/2318-5104.2018.v16.n1.p153

\author{
Paulo César Arcênio Júnior, Caroline Ruschel, Clara Knierim Correia \\ Universidade do Estado de Santa Catarina (UDESC)
}

\section{RESUMO}

O objetivo do estudo foi analisar a produção científica sobre Karatê em língua portuguesa, por meio de uma análise bibliométrica. Foram realizadas buscas nas bases SciELO e BVS-Bireme, associadas a uma busca manual no Google Acadêmico, utilizando-se os seguintes termos: "Karatê", "Caratê", "Artes Marciais", "Karateca” e "Carateca”. Foram incluídos nesta revisão artigos completos publicados em língua portuguesa em periódicos revisados por pares. Foram selecionadas, para a análise bibliométrica, três categorias: periódicos, volume de publicações/autores e temática/participantes/resultados do estudo. A busca retornou 318 estudos, dos quais 25 foram incluídos nesta revisão, publicados entre 1984 e 2017 em periódicos classificados em diferentes estratos do Qualis Capes, variando de C a A2. Em relação aos autores que publicam sobre Karatê no Brasil, a maioria se encontra nas regiões Sul e Sudeste do país. Quanto aos temas, há predomínio daqueles relacionados à biomecânica (análise do tempo de reação e da velocidade de movimento durante a execução de chutes e socos, e da força de preensão manual) e à fisiologia do exercício (análise de lactato e frequência cardíaca, do gasto calórico, da taxa de sudorese e da percepção subjetiva do esforço durante sessões de treinamento e/ou em competição). A análise produção científica sobre o karatê em língua portuguesa permitiu concluir que há predominância de estudos nas áreas temáticas da biomecânica e fisiologia do exercício, que incluíram participantes adultos de diferentes níveis técnicos, principalmente homens de nível avançado. É também possível especular que há um interesse recente e crescente da comunidade científica, principalmente nos últimos 10 anos, em investigar a modalidade sob diferentes perspectivas. Ainda assim, considera-se escassa a produção científica em língua portuguesa, e que ainda há diversos fatores a serem investigados, no sentido de contribuir para o desenvolvimento de uma prática profissional cada vez mais pautada em evidências.

PALAVRAS-CHAVE: Artes Marciais; Karatê; Treinamento.

\section{ABSTRACT}

The aim of this study was to analyze the scientific production on Karate in Portuguese language published in journals indexed in SCIELO and BIREME, through a bibliometric analysis. Searches were carried out in SciELO and BVS-Bireme databases, associated with a manual search in Google Scholar, using the following keywords: "Karatê", "Caratê", "Artes Marciais", "Karateca" and "Carateca". Full articles published in Portuguese language in peer-reviewed journals were included in this study. Three categories were selected for the bibliometric analysis: journals, authors and themes. The search resulted in 318 records, of which 25 were included in this review and were published between 1984 and 2017 in journals classified in different strata of Qualis Capes, ranging from $\mathrm{C}$ to $\mathrm{A} 2$. In relation to the authors, the largest concentration of research groups that publish on Karate is found in the South and Southeast regions of Brazil. Regarding the themes, there is a predominance of those related to biomechanics (analysis of reaction time and movement speed during execution of kicks and punches, and manual grip strength) and exercise physiology (analysis of blood lactate and heart rate, energy expenditure, sweating rate and subjective perception of exertion during training and/or competition sessions). The scientific production about Karate in portuguese language allowed us to concluded that there is a predominance of studies in the biomechanical and exercises research areas, which included adults of different technical levels, mainly men advanced level.

KEYWORDS: Martial Arts; Karate; Training. 


\section{INTRODUÇÃO}

A demanda social pela prática de manifestações relacionadas às artes marciais pode ser evidenciada em diferentes ambientes e dimensões, como em escolas e clubes (PARIZOTTO et al., 2017) e realizada por pessoas em diferentes fases do ciclo vital (CIERNA; LISTAD, 2017; RODRIGUES NETO, 2011). Neste contexto, o Karatê configura-se como uma das artes marciais mais conhecidas e praticadas no mundo (PARIZOTTO et al., 2017), cuja expansão ocorreu de forma rápida ao longo do século XX, principalmente a partir da década de 1920, por intermédio dos esforços de Gichin Funakoshi para a divulgação da arte e pelo reconhecimento desta como método educacional (BARREIRA; MASSIMI, 2003).

O Karatê é uma arte marcial nipônica dividida em estilos, com origem na ilha de Okinawa. A prática tem como objetivo filosófico o desenvolvimento integral do praticante através do treinamento, com foco voltado tanto para os aspectos formadores do caráter quanto para os aspectos relacionados à saúde do indivíduo. Enquanto forma de defesa pessoal, essa arte marcial é constituída de técnicas contundentes como socos, chutes e pontapés (GAVAGAN, SAYERS, 2017; QUINZI et al. 2016; VENCESBRITO et al., 2011). O nível de intensidade e a complexidade das técnicas praticadas podem variar conforme a idade, o gênero e outras peculiaridades dos praticantes, não se restringindo a um perfil pré-estabelecido (CHAABENE et al. 2012; RODRIGUES NETO, 2011). O treinamento de Karatê promove a melhora das qualidades físicas básicas, como velocidade, força, flexibilidade e resistência (CHAABENE et al., 2012) e das qualidades motoras coordenativas, como coordenação e equilíbrio (WITTE et al., 2016).

Sob uma perspectiva pedagógica, o Karatê se mostra uma excelente ferramenta para o desenvolvimento de valores pedagógicos e de tradição, pois nas suas sessões de treinamento são frequentemente estimulados os modos de comportamentos relacionados a verdade, respeito e seriedade (LOPES; TAVARES, 2008). Segundo Cantanhede et al. (2010), há maior facilidade de inserção do Karatê na escola em comparação a outras artes marciais, tendo em vista que pode ser praticada em qualquer espaço livre de obstáculos (dispensando o uso de pisos de amortecimento), e que não é necessário o uso da a vestimenta especial, podendo realizá-la com as roupas que os alunos habitualmente utilizam nas aulas de Educação Física.

Mais recentemente, observa-se a consolidação do Karatê no universo do esporte competitivo, sob a forma de combate simulado com regras definidas para se evitar ferimentos graves. Segundo a Confederação Brasileira de Karatê - CBK (2013), o participante que luta o Karatê em torneios, busca possuir alto tempo de luta, velocidade, técnica e estratégia, além de respeito ao adversário e controle emocional.

De acordo com os diferentes contextos citados, o Karatê configura-se atualmente como uma opção de exercício para fins de condicionamento físico, defesa pessoal, atividade de lazer ou modalidade com fins esportivos. Essa demanda de aplicações faz emergir questionamentos sobre a prática e a necessidade de estudos a fim de compreender os diferentes fenômenos relacionados ao Karatê, e por isso a busca por fontes cientificas se torna indispensável (ROSSI; TIRAPEGUI, 2015). Neste sentido, deve-se associar o conhecimento científico ao treinamento de Karatê a fim de evitar maus hábitos e lesões, e também para promover o desenvolvimento de um domínio técnico com maior agilidade. Por outro lado, é grande a escassez de recursos e estudos relevantes nessa área (CORREIA; FRANCHINI, 2010).

Com o intuito de sintetizar os principais achados sobre a modalidade, este estudo teve como objetivo analisar a produção científica sobre Karatê em língua portuguesa, por meio de uma análise bibliométrica. Investigações semelhantes já foram realizadas por outros autores para modalidades como o taekwondo (PÉREZ-GUTIÉRREZ et al., 2017) e o judô (PESET et al., 2013), porém não foram encontrados estudos dessa natureza abordando o karatê. Para este estudo considerou-se a seguinte pergunta norteadora: Quais as principais características da produção científica sobre karatê publicada em língua portuguesa, considerando-se os periódicos (classificação Qualis e escopo), os autores (distribuição geográfica), o volume de publicações no período analisado, os participantes e os temas investigados nos estudos? Acredita-se que esse tipo de análise pode contribuir para a compreensão do desenvolvimento das áreas de estudo relacionadas ao karatê, e indicar tendências para futuras investigações.

\section{MÉTODOS}

Para identificar os estudos que abordavam o tema de interesse, foram feitas buscas nas bases de dados da Scientific Electronic Library Online (SciELO) e Biblioteca Virtual em Saúde (BVS - Bireme). Adicionalmente, uma busca manual foi realizada no Google Acadêmico. Utilizaram-se os seguintes termos para a busca: "Karatê", 
"Caratê" e "artes marciais", "Karateca" e "Carateca". Para inclusão de estudos nesta revisão, foram utilizados os seguintes critérios: (a) artigos completos publicados em periódicos revisados por pares; (b) artigos publicados em português, até o mês de abril de 2018; (c) estudos transversais, longitudinais, experimentais e/ou estudos de caso que analisem de maneira objetiva os aspectos filosóficos, fisiológicos, biomecânicos, psicológicos, pedagógicos e/ou de epidemiologia de lesões relacionados à prática do karatê; e (d) artigos que considerem, em suas análises, qualquer estilo de Karatê. Foram excluídos os estudos do tipo revisão de literatura.

A avaliação quanto à relevância do artigo foi feita inicialmente pela leitura dos títulos; em seguida, pela leitura do resumo; e, por fim, pela leitura do documento na íntegra. A análise bibliométrica ocorreu em três categorias, sendo:

1) Periódicos: Classificação do periódico na área "Educação Física" do Qualis Periódicos da CAPES, considerado o quadriênio 2013-2016, e área de pesquisa/escopo do periódico;

2) Volume de publicações e autores: Número de publicações por ano e distribuição geográfica dos autores que publicam sobre Karatê no Brasil (considerou-se, para a distribuição, a instituição de filiação do primeiro autor);

3) Temática, participantes e resultados dos estudos: objetivo, características dos participantes (número total, sexo, idade e nível técnico), área temática predominante e principais resultados.

Todas as informações foram extraídas dos próprios artigos, da página das instituições indicadas pelos autores e/ou da Plataforma Sucupira (CAPES, 2018).

\section{RESULTADOS E DISCUSSÃO}

Nos moldes propostos, a busca eletrônica retornou 318 estudos. Após seleção manual, realizada através da leitura dos títulos e da confirmação quanto à disponibilidade do texto completo, foram descartados aqueles repetidos e aqueles que não atendiam aos critérios de inclusão. Na Figura 1 é apresentado o fluxograma das etapas da seleção dos artigos para esta revisão.

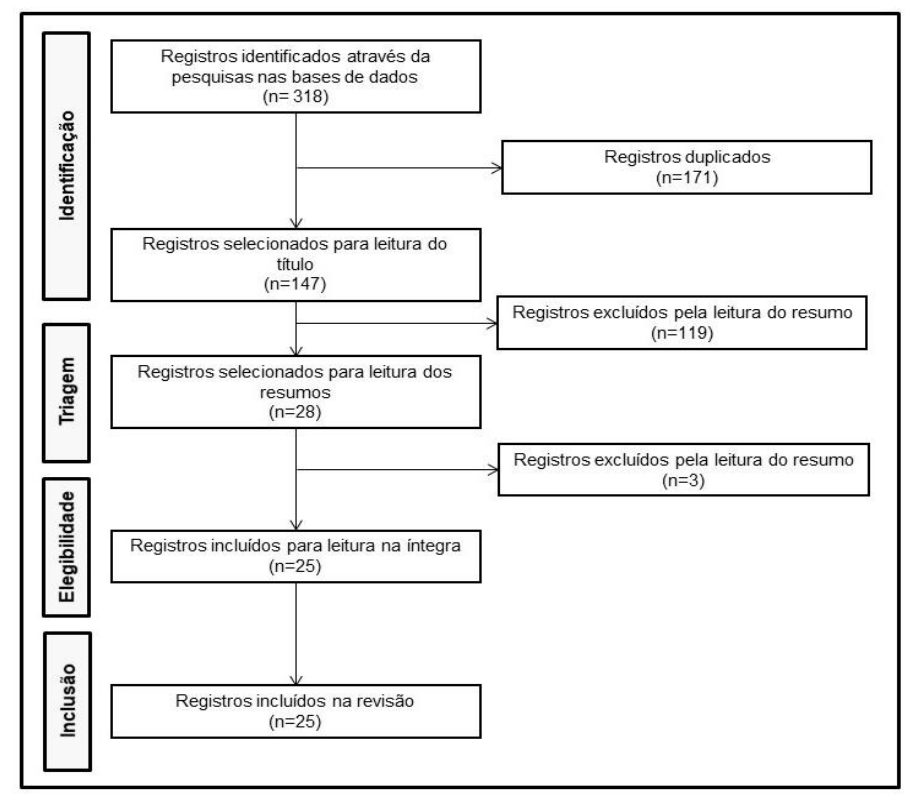

Figura 1. Fluxograma contendo as etapas da revisão de literatura deste estudo.

O resultado final foi um total de 25 artigos incluídos, publicados entre 1984 e 2017. A apresentação e discussão dos resultados está organizada a seguir de acordo com as categorias analisadas, sendo que as duas primeiras foram agrupadas para uma avaliação do cenário da produção científica sobre Karatê em língua 
portuguesa.

\section{Cenário da produção científica}

Na Figura 2 é apresentado o gráfico referente ao número de publicações sobre Karatê, de acordo com o periódico. Três periódicos (Revista Brasileira de Ciência e Movimento, Revista Brasileira de Medicina do Esporte e Journal of Physical Education) concentram a maioria dos artigos publicados, enquanto que 11 periódicos publicaram apenas um estudo sobre a modalidade no período considerado.

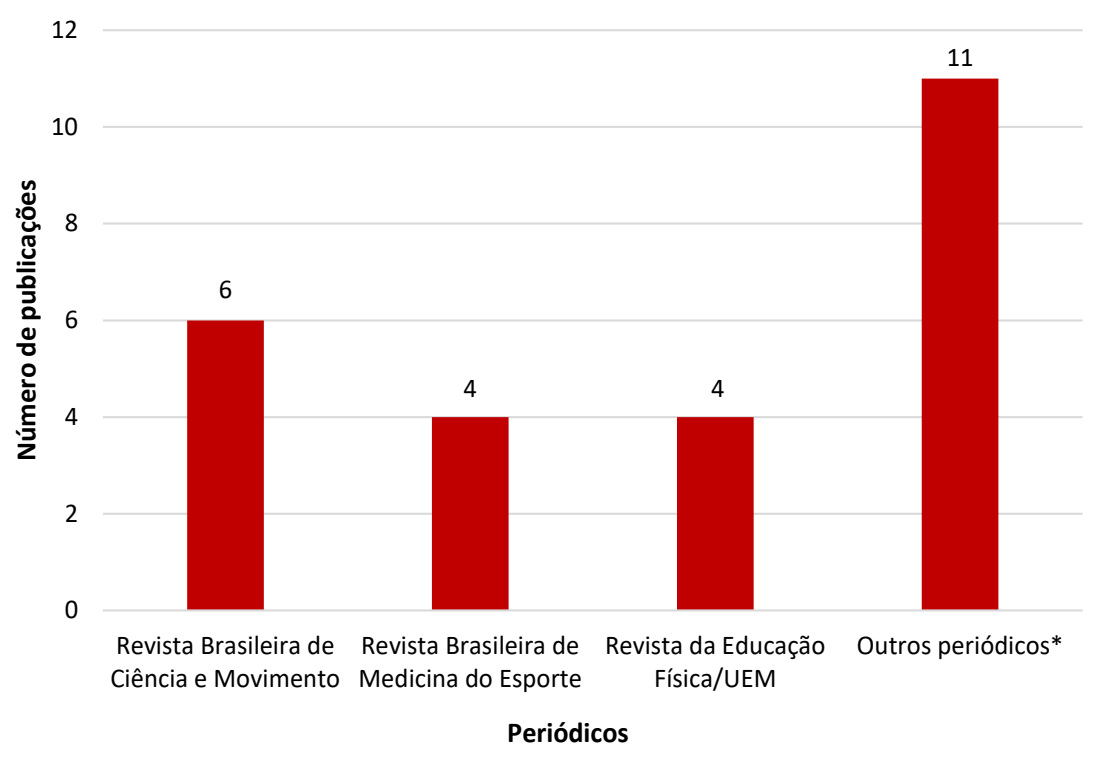

Em relação à área de pesquisa/escopo, há predominância de periódicos com escopo amplo, como atividade física, exercício e esporte $(n=11)$; educação física $(n=06)$, envelhecimento $(n=3)$ e psicologia $(n=2)$. Periódicos voltados para áreas de fisiologia do exercício, reabilitação e saúde pública publicaram apenas um estudo sobre Karatê. Esse resultado é semelhante àquele observado em outras análises da produção científica de artes marciais, prevalecendo as publicações em periódicos das Ciências Esportivas (PÉREZ-GUTIÉRREZ et al., 2017; PESET et al., 2013).

Existem algumas maneiras de classificar um periódico, dentre elas, as métricas avaliadas internacionalmente por meio do Journal Citation Reports - JCR (Thomson Reuters ${ }^{\circledR}$ ) ou SCImago Journal Rank $S J R$. Essas métricas são fórmulas que compreendem basicamente o número de citações dos artigos publicados nos periódicos (MUND; NEUHÄUSLER, 2015). No Brasil, os periódicos podem ser avaliados por meio do Qualis Periódicos da CAPES (CAPES, 2018), com estratos variando de C (mais baixo) até o A1 (mais alto). No Qualis CAPES, os periódicos classificados nos estratos elevados possuem Fator de Impacto, obtendo maior visibilidade no meio acadêmico, por estarem indexadas em bases como Web of Science (Thompson Reuters ${ }^{\circledR}$ ).

Considerando o Qualis Periódicos da CAPES, observa-se que grande parte dos estudos estão publicados em periódicos classificados no estrato $B$, sendo $B 1(n=6), B 2(n=9), B 3(n=1)$ e $B 4(n=2)$. Apenas quatro estudos foram publicados em periódicos de Qualis A2 (Revista Brasileira de Medicina do Esporte, fator de impacto $J C R=0,294)$. Dos 25 estudos, um estudo foi publicado em periódicos com Qualis $C$ e dois foram publicados em periódicos não classificados no Qualis para a área de Educação Física.

O volume de publicações no decorrer dos anos é apresentado na Figura 3. Percebe-se que a primeira publicação encontrada ocorreu no ano de 1984 (n=1), com ápice nos anos de 2013 (n=4) e 2014 (n=4). Ainda, a linha de tendência indica o crescimento das publicações, principalmente nos últimos 10 anos (período no qual 
20 dos 25 estudos incluídos nesta revisão foram publicados).

5

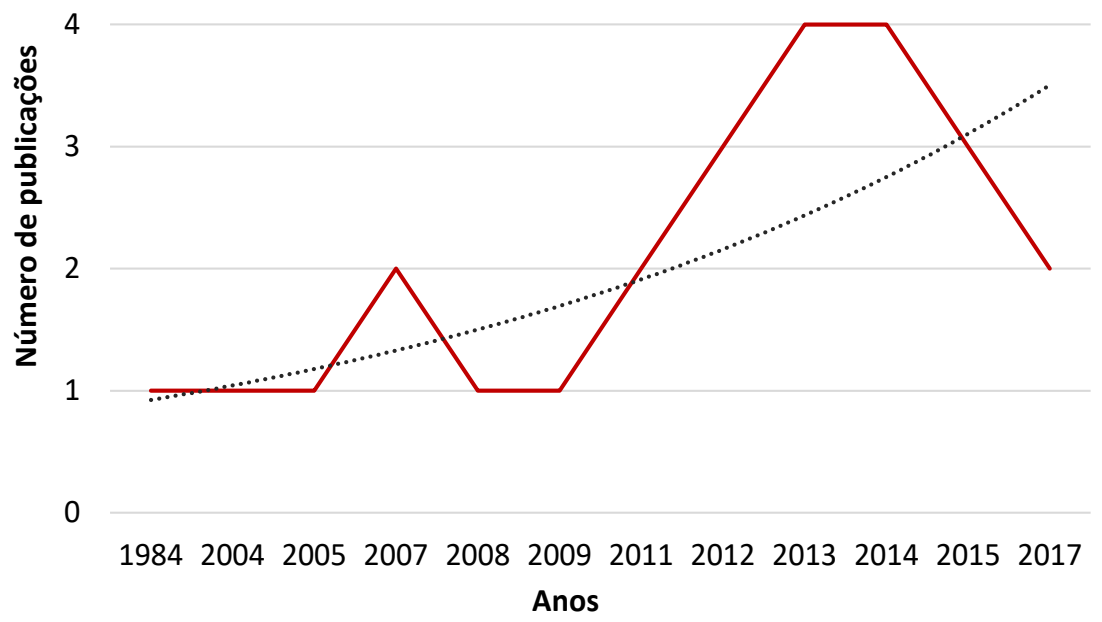

Figura 3. Número de publicações no decorrer dos anos.

A representação da distribuição geográfica dos autores que publicam sobre caratê é apresentada na Figura 4. Percebe-se que a maioria dos estudos sobre a temática foi publicada por autores de instituições das regiões Sudeste e Sul, com $44 \%(n=11)$ e 32\% (n=8), respectivamente.

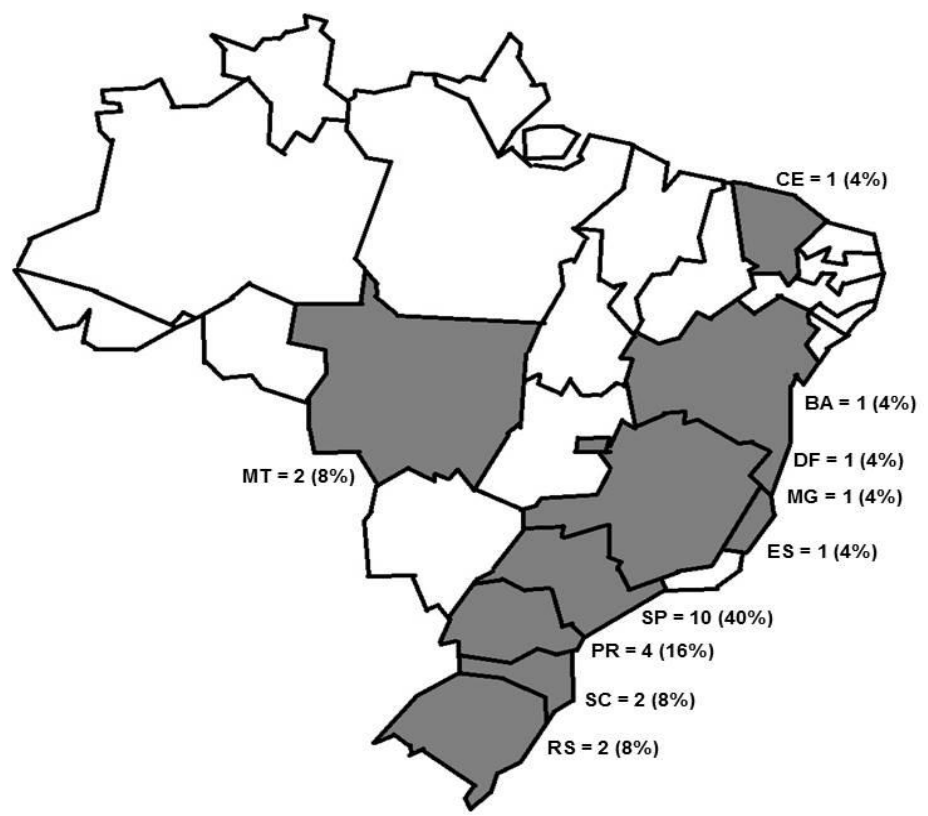

Figura 4. Distribuição geográfica dos grupos de pesquisa que publicam sobre caratê em língua portuguesa.

* Nota: os Estados em branco não foram mencionados na afiliação dos autores dos artigos incluídos nesta revisão. 
O aumento das publicações pode-se dar por diversas razões, dentre elas a criação de pós-graduações e a formação de doutores no Brasil (HELENE; RIBEIRO, 2011). Além disso, Helene e Ribeiro (2011) contribuem afirmando que os investimentos em pesquisa também auxiliam no aumento da produção científica, sendo observado um alto crescimento do fomento dentre os anos de 2002 e 2015 (CAPES, 2015). Com relação à distribuição geográfica dos autores, já se esperava maior concentração de estudos nas regiões Sudeste e Sul, visto que o último censo da CAPES indica que a concentração de Universidades com Programas de Pósgraduação é maior nessas regiões (CAPES, 2018).

Temática, participantes e resultados dos estudos

No Quadro 1 são apresentados os objetivos e as características dos participantes dos estudos incluídos nesta revisão. Os estudos analisaram, em geral, indivíduos do sexo masculino com idade superior a 18 anos. Dentre os 25 estudos consultados, a grande maioria $(n=18)$ inclui na amostra sujeitos já praticantes de Karatê, com pelo menos um ano de experiência, e tem desenhos observacionais e transversais. A maior parte dos estudos ( $n=15,60 \%)$ analisou participantes com nível avançado de prática na modalidade, enquanto que 5 estudos analisaram incluíram indivíduos iniciantes, 2 analisaram indivíduos de nível intermediário e 3 analisaram participantes de dois ou mais níveis de prática. Na Figura 5 são apresentados os dados referentes às áreas temáticas principais de investigação nos estudos incluídos.

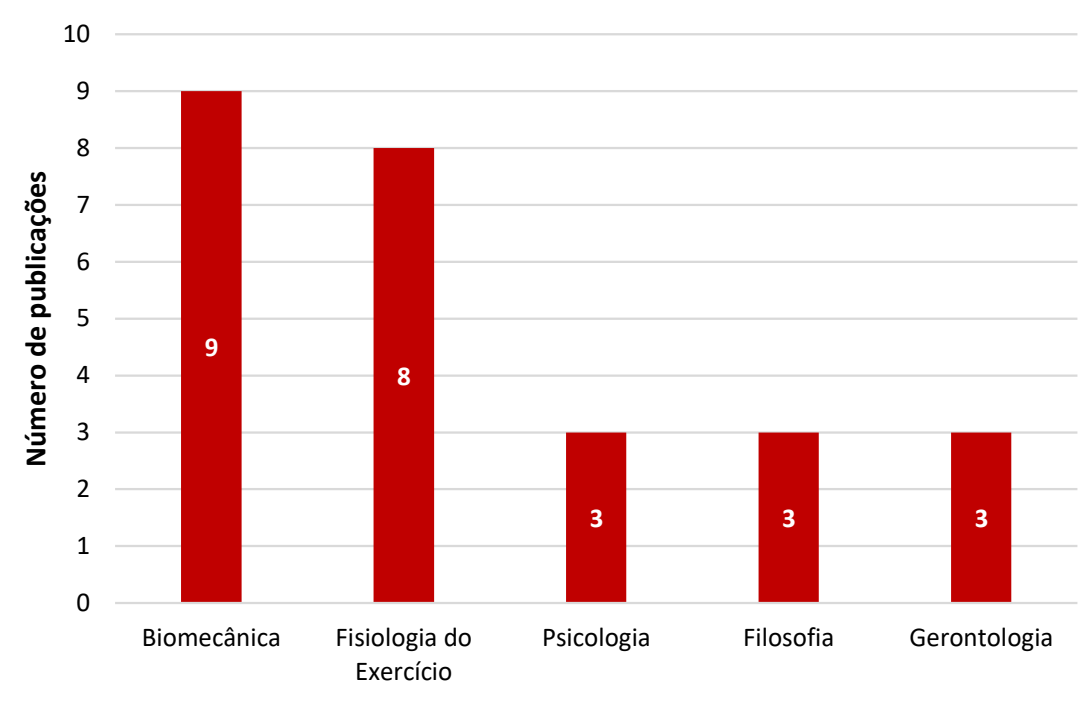

Área de conhecimento

Figura 5. Apresentação das áreas de conhecimento dos estudos incluídos na revisão. Nota: o número total de publicações é superior ao de estudos incluídos na revisão pois alguns estudos incluem mais de uma área de conhecimento.

A Biomecânica foi a área com maior frequência, com nove estudos (36\%), seguida da Fisiologia do Exercício, com oito estudos (32\%). Esses resultados são semelhantes às análises realizadas com a modalidade do Taekwondo (PÉREZ-GUTIÉRREZ et al., 2017), na qual há predomínio de áreas de conhecimento da Biomecânica, Fisiologia e Medicina Esportiva. Os principais resultados dos estudos analisados são apresentados a seguir, agrupados de acordo com as principais áreas temáticas identificadas.

\section{Características biomecânicas}

A dinâmica da luta do Karatê caracteriza-se pela velocidade explosiva dos movimentos exigindo que os atletas tenham que desenvolver um tempo de reação apurado, a fim de tomar decisões e agir em segundos evitando ser golpeados pelo adversário. Essa característica exige do praticante um tempo de ação ou tempo de 


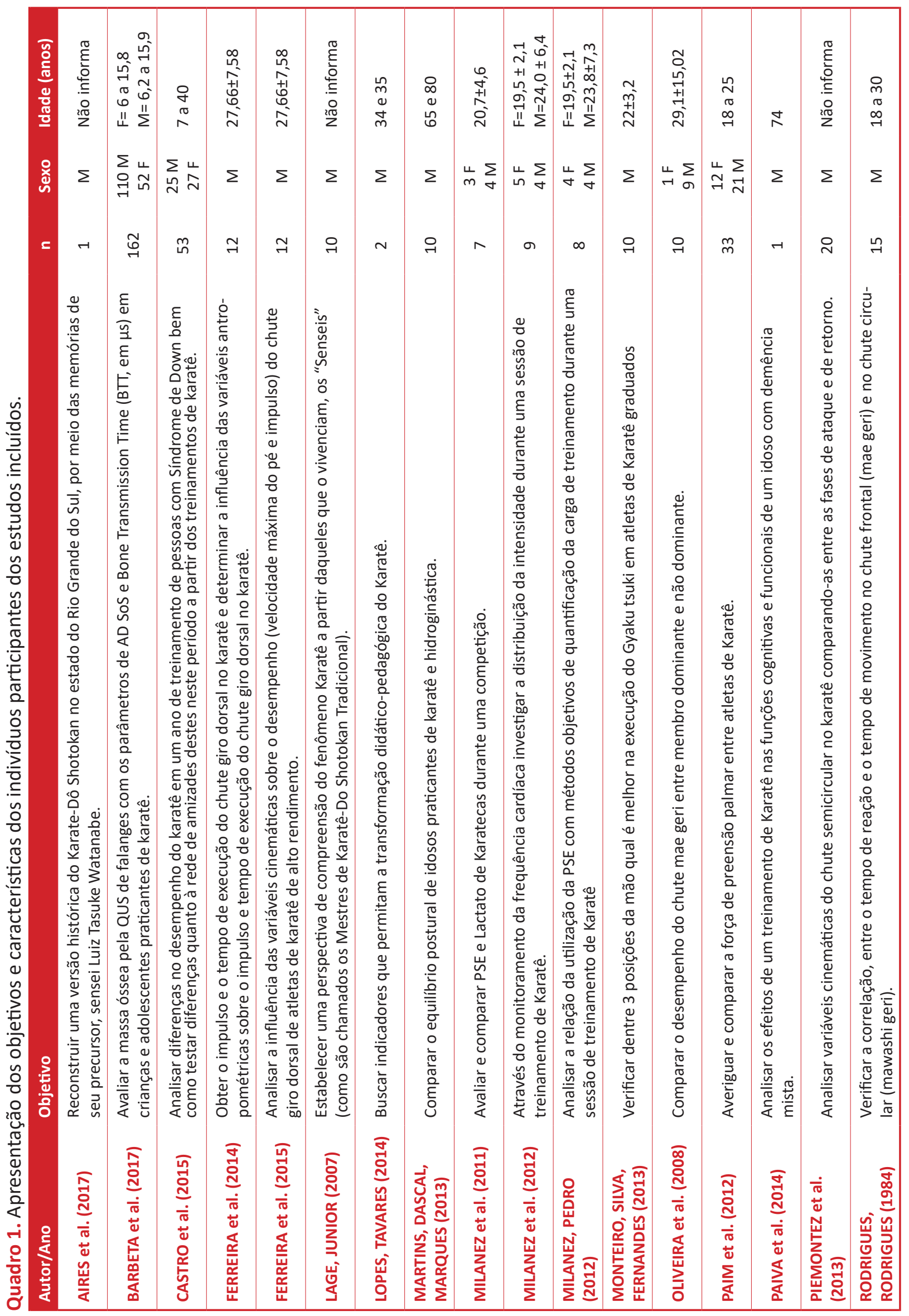


movimento eficiente, a fim de ter o sucesso em conseguir golpear o adversário. Segundo Rodrigues e Rodrigues (1984), o tempo de reação define-se como sendo o tempo de resposta sensorial, ou o espaço de tempo no qual se reconhece, interpreta e responde-se, a um determinado estímulo de origem visual, tátil ou acústica. Buscando verificar se há correlação entre o tempo de reação (TR) e o tempo de movimento (TM) de dois chutes de Karatê (mae geri - chute frontal; e mawashi geri - chute circular), Rodrigues e Rodrigues (1984) realizaram um estudo no qual os participantes realizaram 10 repetições de cada chute contra um saco de pancada a cada estimulo visual proporcionado pela luz de uma lâmpada posicionada atrás do saco de pancada. Os autores verificaram, para todos os atletas, valores de TR (intervalo entre o estímulo e a retirada do pé de ataque do solo) maiores do que os valores do TM (intervalo entre a retirada do pé de ataque do solo e o choque no alvo). Adicionalmente, os autores não verificaram uma correlação significativa entre o TR e o TM. Numa comparação entre os chutes, observou-se que os chutes frontais foram realizados mais rápido do que os chutes circulares.

Oliveira et al. (2008) analisaram a simetria entre os membros durante a execução de chute mae geri (chute frontal) contra uma placa de madeira revestida com borracha do tipo EVA. Os autores não encontraram diferenças significativas entre o membro dominante e o não dominante para nenhuma das variáveis do estudo (velocidade máxima e média do chute, duração do chute, duração de recuperação da perna, altura máxima do joelho, amplitude da variação da altura do quadril, distância inicial e final entre o pé e o alvo e comprimento do passo).

Em relação aos movimentos dos membros superiores, Monteiro, Silva e Fernandes (2013) analisaram o tempo de reação, velocidade de execução do soco e qual a melhor posição da mão em relação à faixa do uniforme durante o soco Gyaku tsuki do Karatê. Os autores reportam que, apesar do posicionamento da mão acima da faixa apresentar melhores resultados tanto no tempo de reação quanto no tempo de execução, as diferenças não foram significativas quando realizada a comparação com as outras posições.

Ferreira et al. (2014), Ferreira et al. (2015) e Piemontez et al. (2013) analisaram variáveis biomecânicas relacionadas ao chute durante diversos gestos motores do karatê. Ferreira et al. (2014) encontram resultados indicando que o impulso e o tempo de execução do movimento durante o chute giro dorsal são influenciados por variáveis físicas, como a massa, estatura e comprimento de membros. Ainda Ferreira et al. (2015) contribuem afirmando que variáveis cinemáticas, como angulações do joelho (ângulo mínimo, ângulo no momento do impacto e amplitude) e velocidade do pé (máxima e no momento de impacto) podem predizer o valor final do impulso durante o chute giro dorsal. Piemontez et al. (2013) comparam variáveis cinemáticas (velocidade e aceleração do joelho, quadril e tornozelo) entre a fase de ataque e retorno durante o chute semicircular e encontram resultados concluindo que a fase de ataque é considerada a mais rápida e a mais essencial durante a luta. Portanto, esses aspectos supracitados devem ser incluídos nos programas de treinamentos dos atletas, vistos que as mesmas podem contribuir para vencer as lutas de karatê.

É importante considerar que grande parte dos estudos que mensuraram o tempo de reação e a velocidade de execução de golpes, seja chute ou soco, foi observado que os autores não levaram em consideração o tamanho dos membros utilizados para execução do golpe. É possível identificar que o comprimento dos membros inferiores possui influência no impulso e no tempo de execução dos chutes (FERREIRA et al., 2014) o que também pode ser especulado para os membros superiores, na execução dos socos.

Considerando a importância da função manual no Karatê, e a relação já demonstrada na literatura entre a força de preensão das mãos e a força total do corpo, Paim et al. (2012) analisaram o perfil da força de preensão palmar em atletas de Karatê e compararam os resultados àqueles observados em um grupo de indivíduos nãoatletas. Segundo os autores, apesar de não haver diferenças estatisticamente significativas entre os grupos, observa-se maior uniformidade entre as médias das preensões palmares direita e esquerda nos atletas de Karatê, o que seria decorrente do fato do karatê ser praticado de maneira bilateral. Considera-se ainda que a não diferença entre o grupo de praticantes de Karatê e o grupo de não praticantes é um fato já esperado, pois o Karatê não faz uso de pegadas como o Judô e o Jiu-jitsu para execução dos golpes, e por isso não proporciona um treinamento para essa qualidade física especificamente.

\section{Demanda fisiológica}

Como em qualquer outra prática física, é comum verificarmos o interesse dos pesquisadores em analisar 
a demanda fisiológica durante sessões de treinamento e/ou em competição, buscando fornecer informações relacionadas ao metabolismo energético predominantemente ativo, ao nível de esforço físico, entre outras variáveis. Neste contexto, Voltarelli et al. (2009) analisaram a cinética do lactato sanguíneo a fim de definir a predominância metabólica do fornecimento energético no Karatê, durante uma sessão de treinamento de 40 minutos (coleta sanguínea antes de iniciar e a cada 5 minutos de treinamento). Os autores observaram nas duas primeiras coletas, 5 e 10 minuto iniciais do treino a concentração de lactato sofreu uma pequena alteração; notaram uma estabilidade do lactato nos minutos 15 a 30; e um aumento exponencial do lactato nos últimos 5 minutos, representando a transição do metabolismo aeróbio para o anaeróbio (35 minutos: 8,7 0,6 mM; 40 minutos: 11,9 $90,7 \mathrm{mM}$ ). De acordo com os autores, os resultados apontaram que durante uma sessão de Karatê o metabolismo aeróbio é predominante.

Buscando verificar a distribuição da intensidade durante uma sessão de treinamento de Karatê com a validade ecológica preservada, Milanez et al. (2012) mensuraram a FC em repouso, submeteram os participantes a um teste incremental para determinar o limiar ventilatório, o ponto de compensação respiratório e a $\mathrm{FC}_{\text {max }}$. 48 horas depois os sujeitos realizaram uma sessão de treinamento de Karatê (91,3 minutos de duração) com monitoramento contínuo da FC. Os resultados mostraram que os praticantes permaneceram a maior parte do tempo de treinamento ( 72,5 minutos, o que equivale a $79,9 \%$ do tempo total) dentro da faixa de $60 \%$ a $80 \%$ da $\mathrm{FC}_{\max }$. Segundo os autores, tais resultados apontam que uma sessão de treinamento de Karatê atende às recomendações do American College of Sports Medicine com relação à intensidade e duração para a prática de exercícios visando à melhora da aptidão cardiorrespiratória, constituindo-se uma alternativa interessante quando tal objetivo é almejado.

Apesar do estudo de Voltarelli et al. (2009) reportar que o metabolismo aeróbico é predominante numa sessão de treinamento de Karatê, na competição o metabolismo anaeróbio tem uma importante participação na demanda energética, conforme aponta o estudo de Milanez et al. (2011). Os autores avaliaram a resposta de percepção subjetiva de esforço e da concentração de lactato numa competição de Karatê, medida após a última luta de cada atleta a cada 2 minutos até o 11으 minuto. Naquela ocasião, cada atleta realizou de uma a três lutas com 2 minutos de duração cada, e com intervalo de 3 minutos entre as lutas. Os autores informam que os valores de concentração de lactato sanguíneo encontrados na condição de competição são duas vezes maiores do que aqueles reportados previamente na literatura para as análises em situação de treinamento, que não foram encontradas diferenças significativas quando comparado o pico de lactato entre mulheres e homens $(8,5 \pm 1,1 \mathrm{mM}$ e $7,0 \pm 1,3 \mathrm{mM}$, para as mulheres e os homens, respectivamente). Adicionalmente, os autores afirmaram que um tempo de intervalo inferior a 11 minutos entre as lutas seria insuficiente para que a concentração de lactato retornasse aos níveis de repouso, o que poderia prejudicar o desempenho do atleta na luta subsequente.

Em relação à PSE, Milanez et al. (2011) utilizaram a escala de Borg 6-20 para a determinação do escore médio percebido pelos atletas considerando-se tidas as lutas, e a escala CR-10 de Borg para a determinação do esforço total durante a competição, medido 30 minutos após o término da última luta. Para os atletas do sexo masculino, a PSE média das lutas foi de 10,2 $\pm 3,0$ u.a., e para as mulheres foi de $13,4 \pm 2,3$ u.a. Adicionalmente, os autores reportaram uma correlação positiva e forte $(r=0,82)$ entre o escore da PSE medida pela escala CR10 e o pico da concentração de lactato, e entre a PSE medida com as duas escalas $(r=0,89)$, indicando, que ambas podem ser aplicadas de maneira eficiente para mensurar o esforço realizado por caratecas durante a competição.

De acordo com Milanez e Pedro (2012), o treinamento ao qual os atletas competitivos são submetidos tem por objetivo maximizar o desempenho esportivo, e para isso é necessário monitorar as cargas de treinamento. Segundo os Franchini et al., (1998), alguns métodos para avaliação do treinamento são realizados muitas vezes em laboratórios, através de testes em esteira, testes em cicloergômetros e simulações de luta. Embora possuam alta validade científica, eles apresentam algumas limitações, como alto custo, técnica invasiva, pouca aplicabilidade no caso de exercícios intermitentes, etc., e muitas vezes se torna inviável realizar em centros de treinamento. Neste sentido evidencia-se na literatura a utilização da PSE como uma ferramenta prática e de baixo custo, indicando alta correlação com variáveis fisiológicas, como nível de lactato (MILANEZ et al., 2011).

Neste contexto, Milanez e Pedro (2012) analisaram as respostas da FC, do lactado e da PSE durante uma sessão de treinamento de Karatê com duração aproximada de 1 hora e 30 minutos, buscando investigar 
a relação entre elas no que tange à quantificação da carga. Segundo os autores, os métodos de quantificação de carga de treinamento baseados em FC e lactato tiveram uma forte correlação com os escores de PSE, o que indica que este último é um método eficiente para a quantificação das cargas de treinamento em atletas de Karatê.

Alguns pontos relevantes que foram observados nos estudos supracitados devem ser mencionados: (1) as análises realizadas em situação de treinamento restringiram-se a avaliar o treino de golpes e contragolpes em duplas ou o treinamento de Kata (luta simulada), o que não corresponde a uma sessão tradicional de treinamento de Karatê comumente aplicado em academias; sendo assim, os resultados obtidos devem ser analisados com cautela, tendo em vista que as condições metodológicas utilizadas não representam na íntegra uma sessão de treinamento da modalidade; (2) nas análises em meio a uma competição, os participantes da amostra realizaram de 1 a 3 lutas, assim sendo houve quem tivesse realizado apenas uma luta e quem tivesse realizado 3, o que pode ter influenciado o resultado geral do grupos de atletas; além disso, acredita-se que uma análise de efeitos da competição exige uma amostra mais significativa, haja vista que os atletas enfrentam adversários de nível técnico distinto, o que pode levar à realização de lutas de diferentes intensidades.

\section{Outros achados sobre temas diversos}

O controle da massa corporal é uma preocupação comum entre os atletas Karatê de alto rendimento, tanto para fins de melhora no desempenho quanto para manter-se na categoria em que competem. Rossi, Tirapegui e Castro (2004) verificaram o efeito de uma dieta de restrição moderada de energia e hiperproteica, em atletas de Karatê de alto nível em preparação para competição internacional, sobre medidas antropométricas e valores da glicemia, ureia e creatinina. Os resultados mostraram que a glicemia, ureia e a creatinina mantiveram-se dentro dos padrões normativos, e os atletas apresentaram uma redução ponderal de peso de 1,0 a 1,8 Kg (redução média de 0,7 Kg por semana, predominantemente de gordura).

Rossi e Tirapegui (2007), durante um evento de Karatê constituído de treinamento e competição, buscaram determinar um perfil antropométrico dos praticantes, calcular o gasto energético total e estabelecer a taxa de sudorese dos atletas. Ao comparar o perfil antropométrico dos atletas brasileiros participantes do estudo àquele reportado em outros estudos realizados, principalmente com atletas japoneses, os autores apontam que os brasileiros apresentam uma tendência a ter maior massa corporal e apresentando menor percentual de gordura, permitindo supor que haja uma maior massa magra, sendo vantajoso para o desempenho no Karatê tendo em vista as maiores demandas de explosão e potência. Quanto ao gasto energético, Rossi e Tirapegui (2007) apontam que este é relevante em um dia de evento competitivo, podendo chegar a $4470 \mathrm{Kcal}$. Os autores sugerem que, devido à combinação do alto gasto calórico com um estresse térmico (possivelmente devido à ineficiência da sudorese relacionada ao tipo de vestimenta e à umidade do ar no dia da competição) e hídrico (reduzidas pausas para hidratação), é necessário que os atletas realizem uma suplementação com repositores eletrolíticos. É importante considerar que o estudo foi realizado em um evento que consistiu de treinamento e competição no mesmo dia, o que não é algo frequente no Karatê. Sendo assim, o grande gasto energético parece ser justificado pelo excesso de atividades no mesmo dia. Adicionalmente, ao comparar os caratecas brasileiros com os japoneses, o estudo não mencionou as diferenças culturais a que ambos os grupos estão expostos, que vão desde hábitos alimentares a aspectos comportamentais, podendo estes ter influência no perfil antropométrico dos atletas.

Buscando fundamentar a utilização do Karatê como uma forma de exercício para a melhora da saúde e a prevenção de doenças como a hipertensão arterial, Sampaio et al. (2013) analisaram o comportamento da pressão arterial (PA) pós-exercício em dois estilos de Karatê diferentes. Os autores estudaram dois grupos de praticantes de Karatê, normotensos, cada um de um estilo diferente: shotokan, denominado no estudo como Karatê Tradicional (KT); e uechi ryu, denominado como Karatê de contato (KC). Os resultados mostraram que ambos os estilos de Karatê promoveram uma redução significativa da PA após o exercício quando comparada à PA em repouso (efeito hipotensivo), sendo que a maior redução foi observada para o grupo de praticantes de KC. Com base nisso, os autores afirmam que o Karatê, em seus diferentes estilos, pode ser utilizado como opção de prevenção, controle e tratamento de disfunções na pressão arterial.

Em um estudo de caso, Paiva et al. (2014) analisaram a influência do treinamento de karatê sobre as 
funções cognitivas e a capacidade funcional de um idoso portador de demência mista. Os resultados apontam a manutenção das funções de memória incidental, imediata e de aprendizagem, o que é de particular interesse no caso de portadores de demência mista, visto que a progressão da doença é evolutiva e irreversível, e que a atenuação do comprometimento cognitivo é uma estratégia de tratamento importante. Em se tratando da capacidade funcional, os autores observaram melhora nas capacidades de equilíbrio estático e dinâmico, o que possivelmente está relacionado à uma diminuição no risco de quedas, à melhora na autonomia na realização de trocas posturais, o que por sua vez pode promover maior independência funcional nas atividades diárias. Os resultados voltados para o equilíbrio postural em idosos também são observados no estudo de Martins, Dascal e Marques (2013), onde a prática de karatê obteve melhoras nessas capacidades, principalmente quando comparados aos idosos praticantes de hidroginástica ou inativos fisicamente. Ainda sobre a prática de karatê para idosos, foram encontrados benefícios físicos (redução do índice de massa corporal e perímetro da cintura) e fisiológicos (pressão arterial e capacidade cardiorrespiratória), além do aumento da força muscular e flexibilidade dos membros inferiores (SQUARCINI et al., 2014).

Em relação às capacidades físicas relacionadas à funcionalidade, a flexibilidade é um requisito para a realização de inúmeras atividades diárias, e durante a prática das artes marciais sua importância é ainda mais notória. Soares et al. (2005) verificaram o nível de flexibilidade entre praticantes de Karatê e de Jiu-jitsu, através da máxima de amplitude articular nos movimentos de extensão horizontal do ombro, flexão da coluna lombar e flexão do quadril. De acordo com os autores, os níveis de flexibilidade do ombro dos atletas das duas modalidades são considerados superiores à média recomendada pela American Academy Of Orthopedic Surgeons, enquanto que os níveis de flexibilidade da coluna e do quadril apresentaram-se dentro dos valores normativos recomendados pela mesma instituição. Quando comparados os resultados entre os praticantes de Karatê e de Jiu-jitsu, não houve diferença significativa, o que sugere que ambas as artes marciais podem promover, além da manutenção, ganhos de flexibilidade aos seus praticantes.

Sob uma perspectiva de análise bastante diferente daquelas apresentadas acima, Rossi e Tirapegui (2015) apontam para a preocupação quanto ao excesso de prática de exercícios físicos, o que pode levar à ocorrência de uma síndrome de dependência. Considerando-se o contexto atual no qual há intensa midiatização das artes marciais, parece ser importante analisar a incidência da síndrome entre praticantes de Karatê, tendo em vista que dentre seus possíveis efeitos negativos associados, segundo Teixeira et al. (2011), estão a distorção da imagem corporal e a ocorrência de transtornos alimentares.

Rossi e Tirapegui (2015) avaliaram a dependência da prática de Karatê em dois grupos de caratecas (iniciantes - faixas coloridas - e avançados - faixas pretas), buscando relacionar essa condição com medidas antropométricas e com a imagem corporal. Os autores encontraram um índice significativamente maior de dependência da prática nos atletas mais experientes, sendo que a insatisfação quanto à imagem corporal foi maior no grupo de atletas menos experientes. Por fim, segundo Rossi e Tirapegui (2015), recomenda-se a aplicação deste tipo de avaliação nas diferentes artes marciais, a fim de determinar diferentes características e suas possíveis consequências no esporte.

Neste sentido, uma consequência negativa relacionada à prática esportiva é a ocorrência de lesões. 0 Karatê esportivo requer uma demanda de golpes com os pés e as mãos através de socos e chutes, e a dinâmica da luta exige movimentos rápidos e explosivos, o que torna a competição um ambiente facilitador de lesões. Souza et al. (2011), considerando as inúmeras competições e expressivo número de praticantes de Karatê e Jiu-Jitsu, verificaram a frequência de lesões em atletas das duas modalidades. Segundo os autores, $88,6 \%$ dos praticantes de Karatê já sofreram alguma lesão, sendo que as mãos e dedos são os locais mais acometidos $(15,5 \%)$, seguidos do pé e dedos dos pés $(12,8 \%)$.

No Jiu-jitsu, $97,5 \%$ dos atletas afirmaram já ter sofrido alguma lesão, sendo os locais mais frequentes o joelho $(16,3 \%)$, o ombro $(14,4 \%)$ e a orelha $(13,3 \%)$. Além disso, devido ao alto impacto nos membros superiores, principalmente nas regiões das mãos, é possível verificar um aumento da massa óssea em crianças e adolescentes praticantes de karatê (BARBETA et al., 2017). Esses resultados contribuem indicando a necessidade de se estudar a saúde óssea dos praticantes, visto que a mesma está associada a padrões morfológicos diferentes do adequado, contribuindo para o aumento de fraturas (BARBETA et al., 2017). É possível observar que as características das lesões parecem estar intimamente relacionadas com a dinâmica de luta de cada modalidade, neste sentido destaca-se a importância dos estudos voltados para as análises 
dos gestos motores da luta, evitando assim diversos tipos de lesões e melhorando a qualidade de vida dos praticantes.

Em se tratando de uma análise filosófica, percebe-se que quatro dos 25 estudos incluídos abordam essa temática (AIRES, 217; LAGE; JUNIOR, 2007; LOPES; TAVARES, 2014). Os três estudos incluem perspectivas distintas, desde a origem e Karatê no Sul Brasil, até a importância da filosofia por trás da modalidade esportiva. Ressalta-se, então, que a modalidade do karatê, pode ser compreendida como uma filosofia de vida, sendo apreciada por meio de experiências, tanto pessoais, quanto diárias (LAGE; JÚNIOR, 2007).

\section{CONSIDERAÇÕES FINAIS}

A análise produção científica sobre o Karatê em língua portuguesa permitiu concluir que há predominância de estudos nas áreas temáticas da biomecânica e fisiologia do exercício, que incluíram participantes adultos de diferentes níveis técnicos, principalmente homens de nível avançado. A produção científica está concentrada principalmente nas regiões Sudeste e Sul do Brasil e é veiculada, em sua maioria, em periódicos de escopo relacionado à Educação Física e Esporte, classificados nos estrados A e B do Qualis CAPES. É também possível especular que há um interesse recente e crescente da comunidade científica, principalmente nos últimos 10 anos, em se analisar a modalidade sob diferentes perspectivas. Acredita-se que os resultados apresentados nesta revisão possam constituir-se uma ferramenta útil para a informação de professores e treinadores de Karatê, de forma a difundir o conhecimento científico sobre a modalidade e contribuir para o desenvolvimento de uma prática profissional cada vez mais pautada em evidências.

\section{REFERÊNCIAS}

AIRES, H.; LEDUR, J. A.; SANTOS, A. F. A.; MAZO, J. Z. A introdução do karate-do shotokan no Rio Grande do Sul: memórias do sensei Watanabe. Revista Brasileira de Ciência e Movimento, Brasília, v. 25 , n. 1, p. 118-28, 2017.

BARREIRA, C. R. A.; MASSIMI, M. As idéias psicopedagógicas e a espiritualidade no karate-do segundo a obra de Gichin Funakoshi. Psicologia: Reflexão e Crítica, Porto Alegre, v. 6, n. 2, p. 379-88, 2003.

BARBETA, C. J. DE O.; GONÇAKVES, E. M.; RIBEIRO, K. D. S.; RIBEIRO, R. ROMAN, E. P.; GUERRAJÚNIOR, G. Massa óssea por ultrassonografia quantitativa de falanges em jovens praticantes de karatê. Revista Paulista de Pediatria, São Paulo, v. 35, n. 4, p. 436-42, 2017.

CAPES. Coordenação de Aperfeiçoamento de Pessoal de Nível Superior. Distribuição de programas de pós-graduação no Brasil. 2016. Disponível em: <https://geocapes.capes.gov.br/geocapes/>. Acessado em: 20 de março de 2018.

CAPES. Coordenação de Aperfeiçoamento de Pessoal de Nível Superior. Investimento da CAPES em bolsas e fomento. 2015. Disponível em: <https://geocapes.capes.gov.br/geocapes/>. Acessado em: 20 de março de 2018.

CAPES. Coordenação de Aperfeiçoamento de Pessoal de Nível Superior. Sobre a avaliação Qualis/ CAPES. 2018. Disponível em: <https://sucupira.capes.gov.br/sucupira/public/index.jsf\#>. Acessado em: 20 de março de 2018.

CASTRO, N. M.; MONTIEL, J. M.; PINIEIRO, L. T. E. Relação entre Karatê e socialização em pessoas com síndrome de Down. Boletim Academia Paulista de Psicologia, São Paulo, v. 35, n. 89, p. 441-59, 2015.

CBK. Confederação Brasileira de Karatê. O karatê esportivo. 2013. Disponível em: <http://www. karatedobrasil.com/histria>. Acessado em: 27 de outubro de 2017.

CHAABENE, H.; HACHANA, Y.; FRANCHINI, E.; MKAOUER, B.; CHAMARI, K. Physical and Physiological profile of elite Karate Athletes. Sports Medicine, Aukland, v. 42, n. 10, p. 829-43, 2012.

CIERNA, D.; LYSTAD, R. P. Epidemiology of competition injuries in youth karate athletes: a prospective cohort study. British Journal of Sports Medicine, Londres, v. 51, n. 17, p. 1285-1288, 2017.

CORREIA, W. R.; FRANCHINI, E. Produção acadêmica em lutas, artes marciais e esportes de combate. 
Motriz, Rio Claro, v. 16, n.1, p.1-9, 2010.

FERREIRA, L.; MARTINS, A. C. V.; PIEMONTEZ, G. R.; DOMENECH, S. C.; GEVAERD, S. C.; BONILLA, A. A. C.; JUNIOR, N. G. B. Influência das características antropométricas sobre o impulso e tempo de execuc,ão do chute giro dorsal do karatê. Revista da Educação Física, Maringá, v. 25, n. 1, p. 33-43, 2014.

FERREIRA, L.; NASCIMENTO JUNIOR, J. R. A.; MARTINS, A. C. V.; PIEMONTEZ, G. R.; BONILLA, A. A. C.; BORGES JUNIOR, N. G. Influência das variáveis cinemáticas sobre o desempenho do chute giro dorsal de atletas de karatê de alto rendimento. Revista Brasileira de Ciência e Movimento, Brasília, v. 23, n. 4, p. 128-38, 2015.

FRANCHINI, E.; TAKITO, M. Y.; LIMA, J. R. P.; HADDAD, S.; KISS, M. A. P. D.; REGAZZI, M.; BOHME, M. T. S. Características fisiológicas em testes laboratoriais e resposta da concentração de lactato sanguíneo em três lutas em judocas das classes juvenil-a, júnior e sênior. Revista Paulista de Educação Física, São Paulo, v. 12, n. 1, p. 5-16, 1998.

GAVAGAN, C. J., SAYERS, M. G. L. A biomechanical analysis of the roundhouse kicking technique of expert practitioners: a comparison between the martial arts disciplines of muay thai, karate, and taekwondo. Plos One, San Franciso, v. 12, n. 8, p. e0182645, 2017.

HELENE, A. F., RIBEIRO, P. L. Brazilian scientific production, financial support, established investigators and doctoral graduates. Scientometrics, Amsterdam, v. 89, p. 677-86, 2011.

LAGE, V.; JUNIOR, L. G. Karatê-do como própria vida. Motriz, Rio Claro, v. 13, n. 1, p. 33-42, 2007.

LOPES, Y. M. E. S.; TAVARES, O. A ação-reflexão-ação dos saberes docentes dos mestres de karatê: construindo indicadores para a transformação da prática pedagógica. Revista da Educação Física, Maringá, v. 25, n. 1, p. 67-79, 2014.

MARTINS, R. DE M.; DASCAL, J. B.; MARQUES, I. Equilíbrio postural em idosos praticantes de hidroginástica e karatê. Revista Brasileira de Geriatria e Gerontologia, Rio de Janeiro, v. 16, n. 1, p. 61-9, 2013.

MILANEZ, V. F.; LIMA, M.; PERANDINI, L.; GONÇALVES, C.; FRANCHINI, E. Avaliação e comparação das respostas da percepção subjetiva de esforço e concentração de lactato em uma competição oficial de karate. Revista da Educação Física, Maringá, v. 22, n. 1, p. 57-64, 2011.

MILANEZ, V. F.; DANTAS, J. L.; CHRISTOFARO, D. G. D.; FERNANDES, R. A. Resposta da frequência cardíaca durante sessão de treinamento de karatê. Revista Brasileira de Medicina do Esporte, São Paulo, v. 18, n. 1, p. 42-5, 2012.

MILANEZ, V. F.; PEDRO, R. E. Aplicação de diferentes métodos de quantificação de cargas durante uma sessão de treinamento de karate. Revista Brasileira de Medicina do Esporte, São Paulo, v. 18, n. 4, p. 278-82, 2012.

MONTEIRO, H. H. D.; SILVA, C. A. da; FERNANDES, T. L. B. Tempo de reação e velocidade do soco em caratecas graduados. FIEP Bulletin On-line, Foz do Iguaçu, v. 84, Especial Edition, p. 1-9, 2013.

MUND, C.; NEUHÄUSLER, P. Towards an early-stage identification of emerging topics in science - the usability of bibliometric characteristics. Journal of Infometrics, v. 9, n. 4, p. 1018-33, 2015.

OLIVEIRA, L. M. de; BARBIERI, F. A.; GOBBI, L. T. B.; DRIGO, A. J. Simetria intermembros no desempenho do chute mae-geri do Karatê. Revista Brasileira de Ciência e Movimento, Brasília, v. 16, n. 4, p. 1-13, 2008.

PAIM, R. DE A.; VIEIRA JUNIIOR, R. C.; TROMBETA, J. C. S.; FILHO, A. D. R. Perfil de força de preensão palmar em atletas de karatê-dô estilo shotokan e indivíduos não atletas. Revista Saúde e Pesquisa, Maringá, v. 5, n. 3, p. 509-15, 2012.

PAIVA, A. C. de S.; VIANA, E. D.; ANDRADE, L. P.; COSTA, T. D. A.; COSTA, J. L. R. A influência de um treinamento de caratê nas funções cognitivas e funcional em idoso com demência mista. Acta Fisiátrica, São Paulo, v. 21, n. 1, p. 41-5, 2014.

PARIZOTTO, P. G. G.; SILVA, A. F. Z.; HEROLD JUNIOR, C.; STAREPRAVO, F. A. O processo de institucionalização e regulamentação de artes marciais orientais no Brasil. Caderno de Educação Física e Esporte, Marechal Cândido Rondon, v. 15, n. 1, p. 53-62, 2017.

PÉREZ-GUtiÉRERZ, M.; BADILLA, P. V.; GUTIÉRREZ-GARCÍA, C.; HERRERA-VAELENZUELA, T. Taekwondo Scientific Production published on the Web of Science (1988-2016): Colaboration and topics. Movimento, Porto Alegre, v. 23, n. 4, p. 1325-40, 2017. 
PESET, F.; FERRER-SAPENA, A.; VILLAMÓN, M.; GONZÁLEZ, L.; TOCA-HERRERA, J.; ALEXANDREBENAVENT, R. Scientific literature analysis of judo in Web of Science. Archives of Budo, Aleje Jerozolimskie, v. 9, n. 2, p. 81-91, 2013.

PIEMONTEZ, G. R.; MARTINS, A. C. V.; MELO, S. I. L.; FERREIRA, L.; REIS, N. F. Cinemática do chute semicircular no karatê: comparação entre as fases de ataque e retorno. Revista da Educação Física, Maringá, v. 24, n. 1, p. 51-9, 2013.

QUINZI, F. ; CAMOMILLA, V.; DI MARIO, A.; FELICI, F.; SBRICCOLI, P. Repeated kicking actions in karate: effect of technical execution in elite practitioners. International Journal of Sports Physiology and Performance, Champaign, v. 11, n. 3, p. 363-9, 2016.

RODRIGUES NETO, V. Os benefícios da prática do Karatê na vida de Idosos. Educação Física em Revista, Taguatinga, v. 5, n. 1, p. 1-7, 2011.

RODRIGUES, S. C. P.; RODRIGUES, I. K. Estudo de correlação entre tempo de reação e tempo de movimento no karatê. Kinesis, Santa Maria, Num. Especial, p. 107-17, 1984.

ROSSI, L.; TIRAPEGUI, J. Avaliação antropométrica de atletas de karatê. Revista Brasileira de Ciências e Movimento, Brasília, v. 15, n. 3, p. 39-46, 2007.

ROSSI, L.; TIRAPEGUI, J. Avaliação da dependência à prática de karatê e a sua relação com o tempo de treino. Revista Brasileira de Medicina do Esporte, São Paulo, v. 21, n. 1, p. 32-35, 2015.

ROSSI, L.; TIRAPEGUI, J.; CASTRO, I. A. DE. Restrição moderada de energia e dieta hiperprotéica promovem redução ponderal em atletas de elite do Karatê. Revista Brasileira de Ciência e Movimento, Brasileira, v. 12, n. 2, p. 69-73, 2004.

SAMPAIO, W. B.; FERREIRA, C. E. S.; MOTA, M. R.; SILVA, F. M. Estudo comparativo da pressão arterial pós-exercício entre o Karate de contato e o Karate tradicional. Revista Brasileira de Ciência e Movimento, Brasília, v. 21, n 4, p. 13-20, 2013.

SOARES, W. D.; SANTOS, R. S.; ALMEIDA, F. N.; TOLENTINO NETO, J. M.; NOVAES, J. S. Determinação dos níveis de flexibilidade em atletas de karatê e jiujitsu. Motricidade, Vila Real, v. 1, n. 4, p. 246-52, 2005.

SOUZA, J. M. C. de; FAIM, F. T.; NAKASHIMA, Y. N.; ALTRUDA, C. R.; MEDEIROS, W. M.; SILVA L. R. Lesões no karate shotokan e no jiu-jitsu: trauma direto versus indireto. Revista Brasileira de Medicina do Esporte, São Paulo, v. 17, n. 2, p. 107-10, 2011.

SQUARCINI, C. F. R.; SILVA, L. W. S.; LEITE, M. C. M.; SOUZA, S. B.; SANTOS, C. E. S.; SILVA, N. M.; PIRES, E. P. O. R.; SOUZA, D. M. Benefícios da prática do caratê para pessoas idosas. Revista Kairós Gerontologia, São Paulo, v. 17, n. 2, p. 27-42, 2014.

VENCESBRITO, A. M.; RODRIGUES, M. A. F.; CORTES, N.; FERNANDES, O.; PEZARAT-CORREIA, P. Kinematic and Electromyographic analyses of a karate punch. Journal of Electromyography and Kinesiology, New York, v. 21, n. 6, p. 1023-29, 2011.

VOltARElli, F. A.; MONTREZOL, P.; SANTOS, F.; GARCIA, A.; COELHO, C. F.; FETT, C. A. Cinética de lactato sanguíneo durante sessões contínuas de lutas simuladas de karatê: predominância aeróbia ou anaeróbia? Revista Brasileira de Prescrição e Fisiologia do Exercício, São Paulo, v. 3, n. 18, p. 566-71, 2009.

WITTE, K.; KROPF, S.; DARIUS, S.; EMMERMACHER, P.; BÖCKELMANN, I. Comparing the effectiveness of karate and fitness training on cognitive functioning in older adults - a randomized controlled trial. Journal of Sports and Health Science, Shangai, v. 5, n. 4, p. 484-90, 2016.

Autor correspondente: Clara Knierim Correia

E-mail: clara.kc@hotmail.com

Recebido: 11 de dezembro de 2017.

Aceito: 04 de maio de 2018. 